\title{
O Uso das Tecnologias Digitais de Informação e Comunicação como Recurso Educacional no Ensino de Enfermagem
} The Use of Digital Information and Communication Technologies as an Educational Resource in Nursing Education

Laís Barreto de Brito Gonçalves ${ }^{\text {* }}$ Antonio Germane Alves Pinto ${ }^{1}$ Sandra Mara Pimentel Duavy ${ }^{1}$ Rauana dos Santos Faustino ${ }^{2}$ Ana Paula Agostinho Alencar ${ }^{3}$ Maria Augusta Vasconcelos Palácio ${ }^{4}$

1 Universidade Regional do Cariri (URCA). Rua Cel. Antônio Luis, 1161.

Crato, CE - Brasil.

*laisynha1@hotmail.com

2 Universidade Estadual do Ceará (UECE). Av. Dr. Silas Munguba, 1700,

Fortaleza, CE - Brasil.

${ }^{3}$ Policlínica Bárbara Pereira de Alencar. Rua José Alves de Oliveira, S/N, Campos Sales, CE - Brasil.

${ }^{4}$ Universidade Federal do Vale do São Francisco (UNIVASF). Rua da Alvorada, S/N, Paulo Afonso, BA - Brasil.

\section{Resumo}

Tecnologias Digitais de Informação e Comunicação (TDIC), quando integradas a práticas pedagógicas, criam espaços de aprendizagem inovadores e colaborativos, promovem a autonomia e a participação ativa do educando. No ensino de Enfermagem, essas habilidades são necessárias à formação de profissionais capazes de responder às demandas de cuidado em saúde da população. Objetiva-se analisar a produção científica sobre a integração das TDIC no processo de ensino-aprendizagem na graduação em Enfermagem. Apresenta-se uma revisão integrativa da literatura, método bibliográfico aplicado à análise qualitativa de 17 artigos, selecionados em critérios temáticos e bibliométricos. Os resultados evidenciam tecnologias digitais integradas ao ensino de Enfermagem e à formação em saúde que indicam a efetividade na integração teoria-prática, suporte especializado do aprendizado e múltiplos objetos virtuais e/ou eletrônicos para a informação e a comunicação. Considera-se que as TDIC têm contribuído para ampliação da relação formativa e intensificado as inovações no ensino de Enfermagem.

Palavras-chave: Tecnologia da informação. Ensino superior. Enfermagem. Educação em enfermagem.

\section{(c) (i)}

Recebido 28/ 12/ 2019

Aceito 07/ 04/ 2020

Publicado 13/04/2020

\section{COMO CITAR ESTE ARTIGO}

ABNT: GONÇALVES, L. B. B. et al.. O Uso das Tecnologias Digitais de Informação e Comunicação como Recurso Educacional no Ensino de Enfermagem. EaD em Foco, V10, e939. 2020. DOI: https://doi.org/10.18264/eadf.v10i1.939 


\section{The Use of Digital Information and Communication Technologies as an Educational Resource in Nursing Education}

\section{Abstract}

Digital information and communication technologies (TDIC) when integrated with pedagogical practices create innovative and collaborative learning spaces, promote autonomy and active participation of the student. In Nursing Education, these skills are necessary for the training of professionals capable of responding to the population's health care demands. The objective is to analyze the scientific production on the integration of these technologies in the teaching-learning process in undergraduate nursing. An integrative literature review is presented, a bibliographic method applied to the qualitative analysis of 17 articles, selected according to thematic and bibliometric criteria. The results show digital technologies integrated with Nursing Education and health education that indicate the effectiveness in the theory-practice integration, specialized learning support and multiple virtual and or electronic objects for information and communication. It is considered that TDIC have contributed to the expansion of the formative relationship and intensified innovations in Nursing Education.

Keywords: Information technology. Higher education. Nursing. Nursing education.

\section{Introdução}

O processo de integração das Tecnologias Digitais de Informação e Comunicação (TDIC) em contextos educativos tem oferecido diferentes possibilidades para recriar espaços de aprendizagem a partir de recursos inovadores que promovem a participação ativa do educando. Essas tecnologias assumem um papel de destaque quando instituídas para a produção e a difusão de informações, além de contribuírem para o desenvolvimento de novas formas de aprender e adquirir conhecimento e habilidades no ensino e nas práticas de saúde (LOPES et al., 2018).

A partir da integração das TDIC no processo de ensino-aprendizagem, pode-se promover um ensino transformador, pautado na autonomia, na construção e no compartilhamento de conhecimento e na valorização do saber do educando. Deve-se investir, cada vez mais, em propostas que contribuam para (re)pensar o ensino de Enfermagem em diferentes perspectivas, uma vez que as mudanças na prática profissional, tão necessárias a este campo, precisam incluir o processo de formação.

Desde que as TDIC começaram a se expandir na sociedade, ocorreram muitas mudanças nas formas de ensinar e aprender nos diferentes níveis de ensino, da escola básica ao ensino superior. No campo educacional, as TDIC trouxeram ganhos na qualificação dos conhecimentos aprendidos e na interatividade no processo de ensino-aprendizagem. Já nos estabelecimentos de assistência à saúde, essas tecnologias são utilizadas tanto para a educação quanto para a pesquisa a distância (KENSKY, 2012; FROTA et al., 2014; BRASIL, 2014).

Além disso, as TDIC oferecem possibilidades para repensar práticas pedagógicas tradicionais e favorecem o protagonismo do educando. Os alunos que nasceram na era digital - os nativos digitais - apresentam 
maior proximidade com as tecnologias, facilidade para usá-las e rapidez de pensamento e raciocínio diante delas. Em contrapartida, sentem-se pouco atraídos pelo modelo tradicional de ensino (MASSON et al., 2014).

Distanciando-se do que se compreende por um conhecimento centrado na cura, para assumir um propósito de produção de saberes integrado, o ensino de Enfermagem perpassa pela reflexão sobre novas mudanças nas práticas pedagógicas, no (re)direcionamento e domínio de habilidades que incluam o uso educativo de novas tecnologias de informação e comunicação (MARTINI et al., 2017).

O desafio de transpor este interesse de transformação do modelo assistencial é encorajado pelas Diretrizes Curriculares Nacionais (DCN), que orientam a formação para atender aos princípios instituídos pelo Sistema Único de Saúde (SUS) (BRASIL, 2001). Dessa forma, destaca-se a necessidade de aprofundar os estudos sobre a integração das TDIC no ensino de Enfermagem, uma vez que esses recursos podem potencializar novas mudanças na formação profissional. Com isso, objetiva-se analisar a produção científica sobre a integração das TDIC no processo de ensino-aprendizagem na graduação em Enfermagem.

\section{Metodologia}

Realizou-se uma revisão integrativa da literatura, a fim de identificar o que tem sido produzido sobre TDIC e ensino de Enfermagem. Para tanto, foram feitas duas pesquisas na Biblioteca Virtual de Saúde (BVS), nas bases de dados LILACS, BDENF e MEDLINE, com associações de descritores diferentes e com a finalidade de alcançar um maior número de resultados. A revisão integrativa é um método que possibilita a incorporação de evidências científicas de maneira sintetizada e ordenada sobre um determinado assunto (MENDES; SILVEIRA; GALVÃO, 2008).

A seguinte pergunta orientou a busca dos artigos: Como as TDIC estão sendo utilizadas no processo de ensino-aprendizagem na graduação em Enfermagem? Na primeira busca, utilizaram-se os descritores "tecnologia da informação", "ensino de Enfermagem" e "ensino superior", com o operador booleano AND. Desta, resultaram 13 produções, e todas estavam disponíveis.

Ao aplicar o filtro "artigos", resultaram 12 publicações, dentre elas, 11 foram publicadas entre 2011 e 2017, e apenas um em 2008. Quanto ao idioma, foram considerados artigos em português, inglês e espanhol. Para tanto, todos os artigos foram incluídos para a etapa seguinte de avaliação.

Após a leitura dos títulos e resumos, foram excluídos três artigos: um por ser duplicado e os outros dois por não responderem ao objetivo da pesquisa. Assim, resultaram para a análise nove artigos, como ilustrado no fluxograma da Figura 1. 


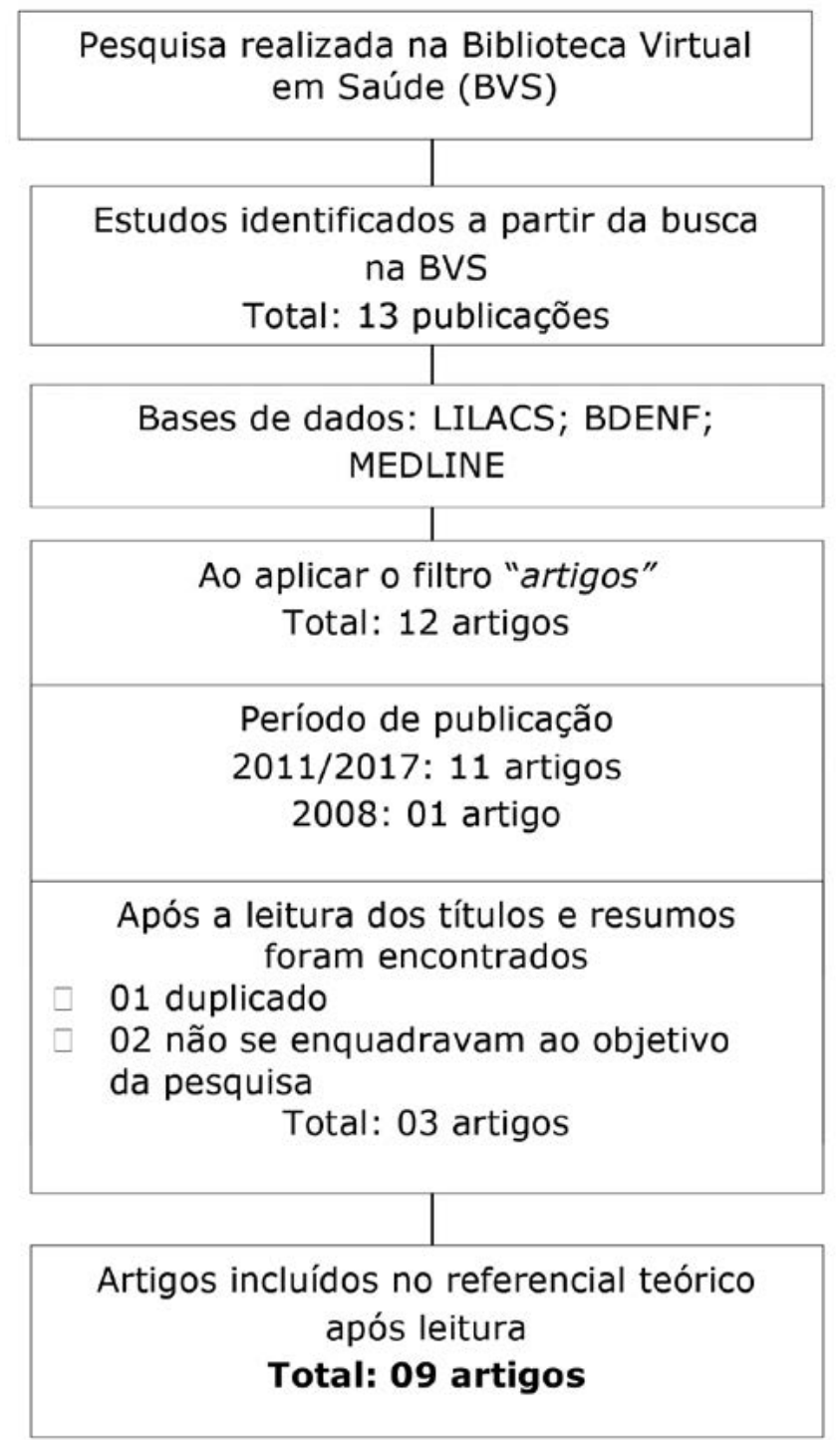

Figura 1: Fluxograma de seleção dos artigos com os descritores: tecnologia da informação AND ensino de Enfermagem AND ensino superior.

Diante disso, optou-se por realizar uma busca incluindo os seguintes descritores: "tecnologia da informação", "ensino de Enfermagem" e "aprendizagem", utilizando o operador booleano AND. Dessa busca, resultaram 58 produções, sendo que apenas 46 estavam disponíveis. Após serem aplicados os critérios de inclusão "artigos" e "publicados nos últimos cinco anos (2013 a 2017)", resultaram 24 artigos, conforme descrito na Figura 2. 


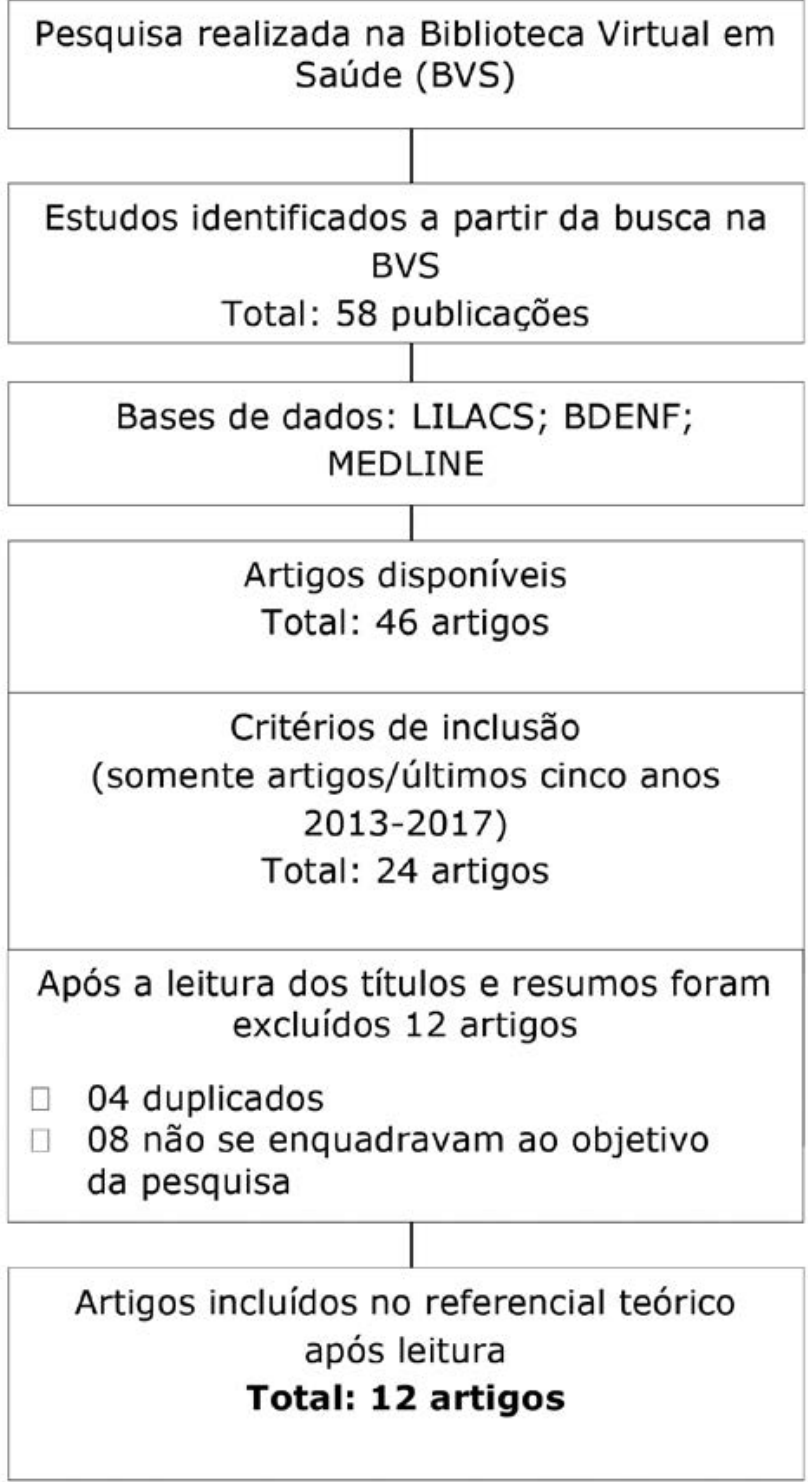

Figura 2: Fluxograma de seleção dos artigos com os descritores: tecnologia da informação AND ensino de Enfermagem AND aprendizagem.

$\mathrm{Na}$ etapa seguinte, fez-se a leitura dos títulos e resumos, excluindo quatro artigos duplicados e oito que não atendiam ao objetivo da pesquisa, resultando em 12 artigos para análise. Além disso, cabe destacar que quatro artigos também apareceram na pesquisa anterior (OLIVEIRA et al., 2017; LEITE et al., 2016; FROTA et al., 2013; SALVADOR; SAKUMOTO; MARIN, 2013).

A fim de aumentar a fidedignidade do estudo, a busca dos artigos foi realizada por dois pesquisadores, assim como o processo de seleção e análise dos artigos também foi compartilhado entre eles. Apresentam-se, com isso, a descrição bibliométrica das publicações, os objetivos e principais resultados, discutidos e argumentados à luz da pergunta da pesquisa.

\section{Resultados e Discussão}

Os 17 artigos selecionados nas duas pesquisas, representados nos quadros 1 e 2, foram publicados em 15 periódicos diferentes. No que se refere ao ano de publicação, cinco artigos $(29,4 \%)$ foram publicados no ano de 2014, já nos anos de 2013 e 2011, foram publicados apenas três artigos (17,6\%) em cada ano. 
Em 2016, foram publicados dois artigos (11,8\%) e nos anos de 2008, 2012, 2015 e 2017 apenas um artigo em cada ano (5,9\%). Em relação aos tipos de estudo, dez (58,8\%) são artigos originais, quatro (23,5\%) são artigos de revisão de literatura e três $(17,6 \%)$ são relatos de experiência.

Quadro 01: Resultados da pesquisa com os descritores tecnologia da informação, ensino de Enfermagem e ensino superior, segundo o título, autores/ano, bases de dados, objetivos e principais resultados.

\begin{tabular}{|c|c|c|c|c|}
\hline Título & $\begin{array}{c}\text { Autores/ } \\
\text { Ano }\end{array}$ & $\begin{array}{c}\text { Base de } \\
\text { dados }\end{array}$ & Objetivo(s) & Principais resultados \\
\hline $\begin{array}{l}\text { Motivação de } \\
\text { alunos de Enfer- } \\
\text { magem no uso } \\
\text { das tecnologias } \\
\text { da informação e } \\
\text { comunicação. }\end{array}$ & $\begin{array}{l}\text { Oliveira, } \\
\text { LMA et al, } \\
2017 .\end{array}$ & $\begin{array}{l}\text { BDENF - } \\
\text { Enferma- } \\
\text { gem } \\
\text { Rev. baia- } \\
\text { na Enf }\end{array}$ & $\begin{array}{l}\text { Mensurar a motiva- } \\
\text { ção no uso de TIC na } \\
\text { Educação a Distância } \\
\text { de alunos do curso de } \\
\text { Enfermagem e avaliar } \\
\text { a interferência de } \\
\text { características pesso- } \\
\text { ais na motivação para } \\
\text { o uso dessas tecnolo- } \\
\text { gias. }\end{array}$ & $\begin{array}{l}\text { A pesquisa revelou níveis } \\
\text { de motivação de baixo } \\
\text { a moderado, com um } \\
\text { entendimento sobre perda } \\
\text { de tempo e incompreen- } \\
\text { são em relação ao uso e } \\
\text { importância das TIC para a } \\
\text { prática profissional futura. }\end{array}$ \\
\hline $\begin{array}{l}\text { Uso da tecnologia } \\
\text { da informação } \\
\text { e comunicação } \\
\text { entre docentes } \\
\text { à luz da teoria } \\
\text { fundamentada } \\
\text { nos dados. }\end{array}$ & $\begin{array}{l}\text { Leite, KNS } \\
\text { et al, } 2016 .\end{array}$ & $\begin{array}{l}\text { BDENF - } \\
\text { Enferma- } \\
\text { gem Rev. } \\
\text { Enferm. } \\
\text { UFPE on- } \\
\text { line }\end{array}$ & $\begin{array}{l}\text { Analisar os discursos } \\
\text { dos docentes sobre } \\
\text { a utilização das TIC } \\
\text { enquanto recurso do } \\
\text { processo de ensino- } \\
\text {-aprendizagem à luz da } \\
\text { Teoria Fundamentada } \\
\text { nos Dados e elaborar } \\
\text { um modelo represen- } \\
\text { tativo a partir de mapa } \\
\text { conceitual. }\end{array}$ & $\begin{array}{l}\text { Os resultados revelam } \\
\text { aspectos sobre resistências } \\
\text { ao uso das TIC, problemas } \\
\text { estruturais relacionados } \\
\text { à inserção e manutenção } \\
\text { do uso, e pouca habilidade } \\
\text { no manuseio de ferra- } \\
\text { mentas digitais. Por outro } \\
\text { lado, sugerem melhoria na } \\
\text { aprendizagem e efetivida- } \\
\text { de no processo de ensino- } \\
\text {-aprendizagem. }\end{array}$ \\
\hline $\begin{array}{l}\text { Construção de } \\
\text { uma tecnologia } \\
\text { educacional para } \\
\text { o ensino de En- } \\
\text { fermagem sobre } \\
\text { punção venosa } \\
\text { periférica. }\end{array}$ & $\begin{array}{l}\text { Frota, NM } \\
\text { et al, } 2013 .\end{array}$ & $\begin{array}{l}\text { LILACS } \\
\text { Rev. } \\
\text { Gaucha. } \\
\text { Enferm }\end{array}$ & $\begin{array}{l}\text { Descrever a cons- } \\
\text { trução de um curso } \\
\text { sobre punção venosa } \\
\text { periférica, utilizando as } \\
\text { Tecnologias da Infor- } \\
\text { mação e Comunicação. }\end{array}$ & $\begin{array}{l}\text { O curso desenvolvido } \\
\text { oferece diferentes ferra- } \\
\text { mentas de interação entre } \\
\text { os alunos e também são } \\
\text { disponibilizados vídeos, } \\
\text { fotografias, hipertextos, hi- } \\
\text { perlinks e exercícios. Dessa } \\
\text { forma, representa uma } \\
\text { ferramenta de suporte aos } \\
\text { estudantes de Enferma- } \\
\text { gem e, consequentemente, } \\
\text { na formação de futuros } \\
\text { enfermeiros na sua prática } \\
\text { assistencial sobre punção } \\
\text { venosa periférica. }\end{array}$ \\
\hline $\begin{array}{l}\text { Uso do Moodle } \\
\text { na Disciplina de } \\
\text { Informática em } \\
\text { Enfermagem. }\end{array}$ & $\begin{array}{l}\text { Salvador, } \\
\text { ME et al, } \\
2013 .\end{array}$ & $\begin{array}{l}\text { LILACS } \\
\text { J. health } \\
\text { inform }\end{array}$ & $\begin{array}{l}\text { Verificar o acesso e } \\
\text { o desempenho dos } \\
\text { alunos de graduação } \\
\text { em Enfermagem ao } \\
\text { Moodle, da Disciplina } \\
\text { de Informática em } \\
\text { Enfermagem. }\end{array}$ & $\begin{array}{l}\text { Os resultados apontam } \\
\text { que a maioria dos alunos } \\
\text { inscritos na disciplina obte- } \\
\text { ve bom desempenho. Em } \\
\text { termos numéricos, dos } 86 \\
\text { alunos inscritos na disci- } \\
\text { plina, } 82 \text { participaram e } 79 \\
\text { obtiveram nota superior } \\
\text { a } 70 . \text { Apenas três alunos } \\
\text { ficaram para recuperação. } \\
\text { O conteúdo que obteve a } \\
\text { melhor média foi Bases de } \\
\text { Dados Bibliográficas }(92,4) \text {, } \\
\text { sendo a menor média, } \\
\text { Telessaúde }(83,4)\end{array}$ \\
\hline
\end{tabular}




\begin{tabular}{|c|c|c|c|c|}
\hline $\begin{array}{l}\text { A produção cien- } \\
\text { tífica de objetos } \\
\text { de aprendizagem } \\
\text { no ensino em } \\
\text { Enfermagem. }\end{array}$ & $\begin{array}{l}\text { Calil, FC et } \\
\text { al, } 2012 .\end{array}$ & $\begin{array}{l}\text { LILACS } \\
\text { J. health } \\
\text { inform }\end{array}$ & $\begin{array}{l}\text { Identificar os estudos } \\
\text { nacionais relacionados } \\
\text { aos tipos de objetos } \\
\text { de aprendizagem (OA) } \\
\text { desenvolvidos e dispo- } \\
\text { nibilizados no ensino } \\
\text { de Enfermagem. }\end{array}$ & $\begin{array}{l}\text { Os tipos de OA produzidos } \\
\text { são softwares, websites e } \\
\text { espaço virtual, nas áreas } \\
\text { de cardiologia, gerencia- } \\
\text { mento em Enfermagem, } \\
\text { neonatologia, administra- } \\
\text { ção de medicamentos e } \\
\text { centro cirúrgico. }\end{array}$ \\
\hline $\begin{array}{l}\text { Estratégias tecno- } \\
\text { lógicas de ensino } \\
\text { associadas ao } \\
\text { treinamento em } \\
\text { Suporte Básico de } \\
\text { Vida. }\end{array}$ & $\begin{array}{l}\text { Mori, S; } \\
\text { Whitaker, } \\
\text { IY; Marin, } \\
\text { HF, } 2011 .\end{array}$ & $\begin{array}{l}\text { LILACS } \\
\text { Acta paul. } \\
\text { enferm }\end{array}$ & $\begin{array}{l}\text { Analisar a eficácia e } \\
\text { as vantagens do uso } \\
\text { dos recursos tecno- } \\
\text { lógicos para o ensino } \\
\text { em Suporte Básico de } \\
\text { Vida (SBV) por meio de } \\
\text { revisão narrativa. }\end{array}$ & $\begin{array}{l}\text { Os recursos utilizados } \\
\text { podem contribuir para } \\
\text { o aprendizado de forma } \\
\text { similar ou superior aos } \\
\text { métodos tradicionais de } \\
\text { ensino. As vantagens ob- } \\
\text { servadas incluem: redução } \\
\text { dos custos de treinamen- } \\
\text { to, facilidade de acesso e } \\
\text { padronização de informa- } \\
\text { ções. }\end{array}$ \\
\hline $\begin{array}{l}\text { Recursos de infor- } \\
\text { mática no ensino } \\
\text { de Enfermagem } \\
\text { sob a perspectiva } \\
\text { de docentes e } \\
\text { gestores universi- } \\
\text { tários. }\end{array}$ & $\begin{array}{l}\text { Azevedo, } \\
\text { DM et al, } \\
2011 .\end{array}$ & $\begin{array}{l}\text { BDENF - } \\
\text { Enferma- } \\
\text { gem } \\
\text { Rev. En- } \\
\text { ferm. UFPE } \\
\text { online }\end{array}$ & $\begin{array}{l}\text { Identificar e discutir os } \\
\text { recursos de informáti- } \\
\text { ca disponíveis para o } \\
\text { ensino de Enfermagem } \\
\text { sob a perspectiva de } \\
\text { educadores e gestores } \\
\text { de uma instituição } \\
\text { federal de ensino } \\
\text { superior. }\end{array}$ & $\begin{array}{l}\text { Os resultados mostram } \\
\text { um entendimento sobre a } \\
\text { importância da informática } \\
\text { no ensino da Enfermagem. } \\
\text { Contudo, } 93 \% \text { dos edu- } \\
\text { cadores indicaram que a } \\
\text { instituição pesquisada não } \\
\text { dispõe de infraestrutura de } \\
\text { informática que contemple } \\
\text { as atividades de ensino. } \\
\text { Por sua vez, } 80 \% \text { dos } \\
\text { gestores afirmam existir in- } \\
\text { fraestrutura de informática } \\
\text { que favorece as atividades } \\
\text { acadêmicas. }\end{array}$ \\
\hline $\begin{array}{l}\text { Tecnologias } \\
\text { digitais no ensino } \\
\text { de graduação em } \\
\text { Enfermagem: as } \\
\text { possibilidades } \\
\text { metodológicas } \\
\text { por docentes. }\end{array}$ & $\begin{array}{l}\text { Cogo, ALP } \\
\text { et al, } 2011 .\end{array}$ & $\begin{array}{l}\text { LILACS } \\
\text { Rev. } \\
\text { Eletrônica } \\
\text { enferm }\end{array}$ & $\begin{array}{l}\text { Descrever as possi- } \\
\text { bilidades metodoló- } \\
\text { gicas na utilização de } \\
\text { tecnologias digitais no } \\
\text { ensino de graduação } \\
\text { em Enfermagem nas } \\
\text { modalidades presen- } \\
\text { cial e a distância. }\end{array}$ & $\begin{array}{l}\text { Existe por parte das } \\
\text { docentes pesquisadas } \\
\text { uma percepção sobre a } \\
\text { relevância da utilização das } \\
\text { tecnologias digitais, em- } \\
\text { bora não as utilizem com } \\
\text { seus alunos. Nesse sentido, } \\
\text { ressalta-se a importância } \\
\text { da educação permanente } \\
\text { dos docentes de cursos } \\
\text { de Enfermagem para que } \\
\text { possam integrar as tecno- } \\
\text { logias em suas atividades } \\
\text { de ensino. }\end{array}$ \\
\hline $\begin{array}{l}\text { Construção de } \\
\text { uma práxis edu- } \\
\text { cativa em infor- } \\
\text { mática na saúde } \\
\text { para o ensino de } \\
\text { graduação. }\end{array}$ & $\begin{array}{l}\text { Cardoso, } \\
\text { JP et al, } \\
2008 .\end{array}$ & $\begin{array}{l}\text { LILACS } \\
\text { Ciênc. Saú- } \\
\text { de Colet }\end{array}$ & $\begin{array}{l}\text { Apresentar a experiên- } \\
\text { cia vivenciada quanto } \\
\text { ao ensino da informa- } \\
\text { ção e da informática } \\
\text { na saúde para a edu- } \\
\text { cação de profissionais } \\
\text { no âmbito dos cursos } \\
\text { de graduação da área } \\
\text { da saúde. }\end{array}$ & $\begin{array}{l}\text { A experiência relatada } \\
\text { mostra que a informática } \\
\text { tem sido integrada em } \\
\text { cursos da área da saúde } \\
\text { com diferentes finalidades, } \\
\text { especificamente, como su- } \\
\text { porte à gestão, ao proces- } \\
\text { so educativo e à pesquisa } \\
\text { em saúde. E, com isso, tem } \\
\text { contribuído para o proces- } \\
\text { so educativo e para uma } \\
\text { reflexão positiva sobre o } \\
\text { uso das TIC na educação. }\end{array}$ \\
\hline
\end{tabular}


Quadro 02: Resultados da pesquisa com os descritores tecnologia da informação, ensino de Enfermagem e aprendizagem, segundo o título, autores/ano, bases de dados, objetivo(s) e principais resultados.

\begin{tabular}{|c|c|c|c|c|}
\hline Título & $\begin{array}{c}\text { Autores/ } \\
\text { Ano }\end{array}$ & $\begin{array}{c}\text { Base de } \\
\text { dados }\end{array}$ & Objetivo(s) & Principais resultados \\
\hline \multicolumn{5}{|c|}{$\begin{array}{c}\text { Motivação de alunos de Enfermagem no uso das tecnologias da informação e comunicação* } \\
\text { Oliveira, LMA et al, } 2017 .\end{array}$} \\
\hline $\begin{array}{l}\text { Desenvolvimento } \\
\text { de objeto de } \\
\text { aprendizagem } \\
\text { para o ensino } \\
\text { de Anatomia em } \\
\text { Enfermagem. }\end{array}$ & $\begin{array}{l}\text { Ribeiro, RL } \\
\text { et al, } 2016 .\end{array}$ & $\begin{array}{l}\text { LILACS } \\
\text { Rev. RENE }\end{array}$ & $\begin{array}{l}\text { Descrever o desenvol- } \\
\text { vimento do objeto de } \\
\text { aprendizagem (OA) } \\
\text { denominado “Com- } \\
\text { plemento Disciplinar } \\
\text { de Anatomia” para o } \\
\text { ensino e a aprendi- } \\
\text { zagem da disciplina } \\
\text { Anatomia. }\end{array}$ & $\begin{array}{l}\text { O OA desenvolvido para o } \\
\text { ensino de anatomia foi a } \\
\text { aula virtual. Esta represen- } \\
\text { tou uma estratégia inovado- } \\
\text { ra, que favorece a autono- } \\
\text { mia no aprendizado e no } \\
\text { manejo das tecnologias no } \\
\text { processo educativo. }\end{array}$ \\
\hline \multicolumn{5}{|c|}{$\begin{array}{l}\text { Uso da tecnologia da informação e comunicação entre docentes à luz da teoria } \\
\text { fundamentada nos dados* } \\
\text { Leite, KNS et al, } 2016 .\end{array}$} \\
\hline $\begin{array}{l}\text { Recursos } \\
\text { educativos } \\
\text { abiertos para } \\
\text { la comunidade } \\
\text { virtual de } \\
\text { enfermeria. }\end{array}$ & $\begin{array}{l}\text { Vidal, } \\
\text { MNV, } \\
2015 .\end{array}$ & $\begin{array}{l}\text { LILACS } \\
\text { Educ. } \\
\text { Med. } \\
\text { Super }\end{array}$ & $\begin{array}{l}\text { Mostrar as potencia- } \\
\text { lidades dos Recursos } \\
\text { Educacionais Abertos } \\
\text { (REA) obtidos a partir } \\
\text { de atividades do proje- } \\
\text { to de telenfermagem. }\end{array}$ & $\begin{array}{l}\text { Considerando as necessida- } \\
\text { des de professores, estudan- } \\
\text { tes e comunidade virtual de } \\
\text { Enfermagem, esses recursos } \\
\text { permitem que a equipe de } \\
\text { Enfermagem identifique, } \\
\text { de forma progressiva, o } \\
\text { potencial e o escopo dessa } \\
\text { ferramenta, para intercâm- } \\
\text { bio científico e atividades } \\
\text { acadêmicas no ensino de } \\
\text { Enfermagem. }\end{array}$ \\
\hline $\begin{array}{l}\text { Laboratório de } \\
\text { Enfermagem: } \\
\text { estratégias } \\
\text { criativas de } \\
\text { simulações como } \\
\text { procedimento } \\
\text { pedagógico. }\end{array}$ & $\begin{array}{l}\text { Figueiredo, } \\
\text { AE, } 2014 .\end{array}$ & $\begin{array}{l}\text { BDENF - } \\
\text { Enferma- } \\
\text { gem Rev. } \\
\text { Enferm } \\
\text { UFSM }\end{array}$ & $\begin{array}{l}\text { Relatar a experiência } \\
\text { da utilização de Ipads } \\
\text { como ferramenta } \\
\text { pedagógica e criati- } \\
\text { va em situações de } \\
\text { simulação de aprendi- } \\
\text { zagem no Laboratório } \\
\text { de Cuidado Humano } \\
\text { (LCH) do curso de } \\
\text { Enfermagem. }\end{array}$ & $\begin{array}{l}\text { Com o uso dessa ferramen- } \\
\text { ta, observou-se aumento } \\
\text { de } 50 \% \text { na procura ao LCH } \\
\text { para simulação de técnicas } \\
\text { como recurso de aprendi- } \\
\text { zado. Segundo os alunos } \\
\text { participantes, houve maior } \\
\text { satisfação com o aprendiza- } \\
\text { do de habilidades e } \\
\text { raciocínio clínico. }\end{array}$ \\
\hline $\begin{array}{l}\text { Construção de } \\
\text { objetos virtuais } \\
\text { de aprendizagem } \\
\text { para o ensino da } \\
\text { história em } \\
\text { Enfermagem. }\end{array}$ & $\begin{array}{l}\text { Masson, } \\
\text { VA, } 2014 .\end{array}$ & $\begin{array}{l}\text { LILACS } \\
\text { Rev. Min. } \\
\text { Enferm }\end{array}$ & $\begin{array}{l}\text { Descrever o } \\
\text { desenvolvimento de } \\
\text { objetos virtuais de } \\
\text { aprendizagem para o } \\
\text { ensino da História da } \\
\text { Enfermagem. }\end{array}$ & $\begin{array}{l}\text { O objeto virtual de apren- } \\
\text { dizagem desenvolvido para } \\
\text { trabalhar o ensino da "Histó- } \\
\text { ria da Enfermagem", visando } \\
\text { à facilitação da aprendi- } \\
\text { zagem de maneira ativa, } \\
\text { inovadora e problematiza- } \\
\text { dora. Os resultados revelam } \\
\text { a contribuição para adoção } \\
\text { de práticas educacionais } \\
\text { pautadas no uso de tecnolo- } \\
\text { gias de informação, possibi- } \\
\text { litando novas perspectivas } \\
\text { para o ensino da "História } \\
\text { da Enfermagem" e para a } \\
\text { reflexão sobre a identidade } \\
\text { profissional. }\end{array}$ \\
\hline
\end{tabular}




\begin{tabular}{|c|c|c|c|c|}
\hline $\begin{array}{l}\text { Hipermídia } \\
\text { educacional } \\
\text { sobre punção } \\
\text { venosa periférica: } \\
\text { perspectiva de } \\
\text { acadêmicos de } \\
\text { Enfermagem. }\end{array}$ & $\begin{array}{l}\text { Frota, NM } \\
\text { et al, } 2014 .\end{array}$ & $\begin{array}{l}\text { LILACS } \\
\text { Express. } \\
\text { Cogitare. } \\
\text { Enferm }\end{array}$ & $\begin{array}{l}\text { Identificar a opinião } \\
\text { de estudantes quanto } \\
\text { à utilização de uma hi- } \\
\text { permídia educacional } \\
\text { sobre punção venosa } \\
\text { periférica no ensino de } \\
\text { Enfermagem. }\end{array}$ & $\begin{array}{l}\text { O uso da hipermídia revelou } \\
\text { resultados positivos, pois } \\
\text { a maioria dos acadêmicos } \\
\text { relatou que o material } \\
\text { contribuiu para aprendiza- } \\
\text { gem, autonomia e intera- } \\
\text { tividade no momento de } \\
\text { estudar. Entretanto, alguns } \\
\text { relataram dificuldade de } \\
\text { acesso à hipermídia relacio- } \\
\text { nada, principalmente, } \\
\text { o servidor utilizado. }\end{array}$ \\
\hline $\begin{array}{l}\text { Exploring } \\
\text { the use of } \\
\text { information and } \\
\text { communication } \\
\text { technologies and } \\
\text { social networks } \\
\text { among university } \\
\text { nursing faculty } \\
\text { staff. An opinion } \\
\text { survey. }\end{array}$ & $\begin{array}{l}\text { Fernán- } \\
\text { des-Ale- } \\
\text { mán, JL et } \\
\text { al, } 2014 .\end{array}$ & $\begin{array}{l}\text { LILACS In- } \\
\text { vest. Educ. } \\
\text { Enferm }\end{array}$ & $\begin{array}{l}\text { Analisar o uso das TIC } \\
\text { e das redes sociais } \\
\text { entre os docentes de } \\
\text { Enfermagem da uni- } \\
\text { versidade na Espanha. }\end{array}$ & $\begin{array}{l}\text { O corpo docente de } \\
\text { Enfermagem está envidan- } \\
\text { do grandes esforços para } \\
\text { enfrentar os novos desafios } \\
\text { impostos pelas TIC para } \\
\text { formar os profissionais do } \\
\text { século XXI. É fundamental } \\
\text { prestar atenção especial à } \\
\text { melhoria das habilidades do } \\
\text { corpo docente universitário } \\
\text { na gestão das TIC. }\end{array}$ \\
\hline $\begin{array}{l}\text { The nursing } \\
\text { educator's role } \\
\text { in e-learning: a } \\
\text { literature review. }\end{array}$ & $\begin{array}{l}\text { Koch, LF, } \\
2014 .\end{array}$ & $\begin{array}{l}\text { MEDLINE } \\
\text { Nurse } \\
\text { Educ } \\
\text { Enferm }\end{array}$ & $\begin{array}{l}\text { Este artigo procura } \\
\text { responder à seguinte } \\
\text { pergunta: Como o } \\
\text { e-learning transforma } \\
\text { o papel dos enfermei- } \\
\text { ros educadores? }\end{array}$ & $\begin{array}{l}\text { A literatura apresentada } \\
\text { examina o papel do educa- } \\
\text { dor no e-learning do ponto } \\
\text { de vista teórico. Observa-se } \\
\text { uma escassez de pesquisas } \\
\text { empíricas relacionadas dire- } \\
\text { tamente ao papel do educa- } \\
\text { dor. O e-learning ainda é tão } \\
\text { inovador que suas compe- } \\
\text { tências ainda estão sendo } \\
\text { definidas, principalmente, } \\
\text { no campo da Enfermagem. }\end{array}$ \\
\hline \multicolumn{5}{|c|}{$\begin{array}{l}\text { Construção de uma tecnologia educacional para o ensino de Enfermagem sobre } \\
\text { punção venosa periférica* } \\
\text { Frota, NM et al, 2013. }\end{array}$} \\
\hline $\begin{array}{l}\text { Recursos tecnoló- } \\
\text { gicos na educação } \\
\text { em Enfermagem. }\end{array}$ & $\begin{array}{l}\text { Tobase, L } \\
\text { et al, } 2013 .\end{array}$ & $\begin{array}{l}\text { LILACS } \\
\text { J. health } \\
\text { inform }\end{array}$ & $\begin{array}{l}\text { Identificar a utilização } \\
\text { dos recursos tecnoló- } \\
\text { gicos na educação em } \\
\text { Enfermagem. }\end{array}$ & $\begin{array}{l}\text { A maioria dos temas } \\
\text { abordados reflete sobre } \\
\text { práticas pedagógicas, EAD } \\
\text { e objetos de aprendizagem } \\
(\mathrm{OA}) \text { aplicados nas áreas de } \\
\text { ensino em Enfermagem e } \\
\text { educação permanente. }\end{array}$ \\
\hline
\end{tabular}

*Os artigos em destaque apresentam-se repetidos no quadro 1.

Após a análise dos artigos, optou-se por categorizá-los em relação às evidências indicadas para o problema em estudo. Os manuscritos foram classificados em três categorias: "Desenvolvimento e o uso de recursos educativos mediados pelas TDIC"; "As TDIC na prática docente no ensino de Enfermagem" e "Percepções sobre a integração das Tecnologias Digitais de Informação e Comunicação no ensino de Enfermagem". 


\section{Desenvolvimento e o uso de recursos educativos mediados pelas TDIC}

O processo de inclusão das TDIC no ensino busca favorecer a difusão das informações. As tecnologias podem trazer benefícios à educação, sendo necessário que tais recursos adequem-se às práticas pedagógicas, para que assim estejam a serviço dos objetivos propostos pelo ensino e não somente como ferramentas isoladas ou determinantes no processo educativo.

Nesse sentido, os espaços educativos indutores de diálogo favorecem a interação entre professor e aluno, ou seja, transformam e melhoram a comunicação entre os sujeitos envolvidos. Assim, as tecnologias surgem para mediar e oferecer suporte, sendo essencial permear a reflexão sobre os Objetos de Aprendizagem (OA) e seus usos no processo de construção nos quais estão sendo incorporados, conforme apresentado por Calil (2012).

Em relação aos OA desenvolvidos e disponibilizados no ensino de Enfermagem, entre 12 artigos selecionados em pesquisa de revisão integrativa, nove eram sobre o desenvolvimento de softwares, dois sobre websites e apenas um sobre espaço virtual interativo (CALIL, 2012). Percebeu-se que os OA foram utilizados em áreas de conhecimentos distintos no ensino de Enfermagem, sendo elas: Cardiologia, Emergência, Neonatologia, Gestão, Administração de medicamentos e no processo de Sistematização da Assistência de Enfermagem (SAE). Os resultados revelaram importantes usos dos OA no ensino de Enfermagem, principalmente o estímulo à realização de novas pesquisas sobre o tema (CALIL, 2012), sugerindo uma pluralidade de ferramentas e usos em diferentes contextos, com possibilidades de adaptação às disciplinas ou aos campos de atuação, sejam atividades teóricas ou práticas.

Com a necessidade de melhorar a aplicabilidade dos conteúdos abordados em uma disciplina, a pesquisa sobre a criação de um objeto virtual de aprendizagem, denominado "Complemento Disciplinar de Anatomia", teve como propósito avaliar o desenvolvimento desse recurso na disciplina de Anatomia a partir da integração das tecnologias digitais. A construção desse objeto virtual se deu por meio da utilização de imagens e textos que ilustrassem e exemplificassem os conteúdos. A proposta apresenta-se como uma ação de formação continuada, na qual sua construção se deu coletivamente. Em compartilhamento com os discentes de outros semestres, explicita-se o intuito de ampliar o conhecimento daqueles interessados na temática abordada (RIBEIRO et al., 2016). Os OA também foram apresentados por Masson (2014) a partir da integração em uma disciplina de História da Enfermagem. Nesse estudo, o uso da tecnologia, além de oferecer possibilidades de abordagem sobre o conteúdo, contribuiu para a reflexão no processo de construção da identidade profissional.

A ideia da utilização de materiais didáticos tecnológicos que facilitem a compreensão de conteúdos surge como uma alternativa contínua de educação centrada na aprendizagem significativa. Enfatiza-se a experiência acerca da construção de objetos virtuais de aprendizagem, destacando que a disponibilização de conteúdo on-line juntamente à utilização de recursos visuais possibilita uma melhor assimilação das informações (BRASIL, 2014).

Em um estudo sobre a eficácia e as vantagens do uso dos recursos tecnológicos para o ensino em Suporte Básico de Vida (SBV), foram analisados 30 artigos que utilizaram ferramentas digitais no treinamento em SBV (MORI; WHITAKER; MARIN, 2011). As ferramentas mais utilizadas foram: vídeo, CD-ROM, DVD, websites e programas computacionais. Ao considerar a contribuição desses recursos no processo de ensino-aprendizagem, identificou-se que sua utilização viabiliza o acesso a informações básicas e avançadas sobre SBV, possibilitando que "os conteúdos sejam revistos e em alguns deles também é possível ao usuário interagir com o sistema, por meio de simulações e questionários, além de tornar possível a ilustração dinâmica, por intermédio de vídeos e sons" (MORI; WHITAKER; MARIN, 2011, p. 724). A partir desses resultados, os autores discutem que os recursos utilizados podem contribuir para o aprendizado de forma similar ou superior aos métodos tradicionais de ensino (MORI; WHITAKER; MARIN, 2011, p. 724). 
Em uma pesquisa acerca do desempenho de discentes na disciplina "Informática em Enfermagem", foi avaliada a integração de ambientes virtuais de aprendizagem em práticas educativas (SALVADOR; SAKUMOTO; MARIN, 2013). O Moodle, ferramenta avaliada, foi considerado uma tecnologia vantajosa por oferecer diversas formas para recriar um ambiente virtual de aprendizagem realista e dinâmico. Em relação à participação dos alunos e professores ao operar tais métodos, a aprendizagem colaborativa mediada pela comunicação tecnológica interfere positivamente na experiência dos envolvidos, pois consente o compartilhamento de experiências em ambientes coexistentes criados pelas tecnologias digitais.

No âmbito assistencial, a elaboração de um curso sobre Punção Venosa Periférica (PVC) elucida que "a construção de cursos na área da saúde com recursos tecnológicos mostra uma variada forma de abordar os temas emergentes e específicos na qualificação de estudantes" (FROTA et al., 2014, p. 33). O que também é reforçado em um estudo no qual se evidencia que "interfaces dinâmicas e atraentes garantem uma comunicação eficaz, desafiando a capacidade de compreensão, avaliação e reflexão do aluno" (SALVADOR; SAKUMOTO; MARIN, 2013, p. 122). Considerando a necessidade de um feedback diante do que se implementa em determinados ambientes educacionais, torna-se pertinente realizar uma avaliação, uma revisão dos conhecimentos compreendidos, estabelecendo uma relação entre o processo de aprendizagem adquirida e a metodologia aplicada (FROTA et al., 2013).

Entre as tecnologias para formação em saúde, tem-se a experiência da simulação realística em procedimentos e cuidados de Enfermagem fazendo o uso de dispositivos móveis. Para sua execução, são realizadas técnicas de simulação com o intuito de fortalecer o aprendizado, como descritas: ensino de habilidades por intermédio de vídeos; reflexão técnica, como recurso a ser desenvolvido por meio de discussões dos conteúdos, na qual os alunos filmavam os procedimentos e, em seguida, analisavam as filmagens e identificavam possíveis erros, acertos e principais dificuldades; por fim, o uso de aplicativos de ausculta cardíaca, pulmonar e abdominal. O uso desses recursos possibilitou uma aprendizagem mais realista, preparando os alunos para possíveis situações-problemas identificadas na prática profissional cotidiana (FIGUEIREDO, 2014).

A integração virtual se apresenta também nas potencialidades de Recursos Educativos Abertos (REA), na modalidade de teleconferências, aplicados em um projeto de Telenfermagem. Os REA podem ser conteúdos educativos, como cursos completos, materiais multimídias, software para produção de conteúdos educativos e recursos de implementação que promovem a publicação aberta dos materiais, bem como na comunicação para a gestão do conhecimento (VIDAL, 2015).

\section{As TDIC na prática docente no ensino de Enfermagem}

Na percepção de docentes universitários na área de Enfermagem sobre o uso das TDIC como recursos didáticos, a prática docente apresenta significativas diferenças entre os níveis de ensino de mestrado e doutorado em relação ao domínio das tecnologias. Os professores em nível de mestrado, especificamente, apresentam duas vezes mais probabilidade de gerenciar as TDIC. Além disso, 63,64\% dos participantes afirmam utilizar a internet para realizar buscas por informações, treinamento e como recurso para facilitar a aprendizagem, enquanto $72,7 \%$ para uso de comunicação, como e-mails e plataformas virtuais (FERNÁNDES-ALEMÁN et al., 2014).

Na utilização da informática como suporte à pesquisa em saúde, é viabilizada uma expansão interdisciplinar e enriquecedora no processo de construção e aquisição de conhecimento, além de "oferecer ao acadêmico a vivência de novas perspectivas no uso das TIC, observando um conjunto de possibilidades para a sua práxis discente e de profissional de saúde em formação" (CARDOSO et al., 2008, p. 287).

Em relação à experiência de alunos de cursos de graduação, Cardoso et al. (2008) contextualizam três abordagens de uso das tecnologias na formação e na prática profissional: a informática como suporte ao 
processo educativo, como suporte à pesquisa em saúde e como suporte à gestão. No processo educativo, a informática tem sido integrada ao desenvolvimento de websites relacionados com a saúde e com o uso de um shell de inteligência artificial, que objetiva desenvolver sistemas especialistas na área da saúde. Em relação à pesquisa em saúde, durante o curso, os alunos podem ter acesso a diferentes ferramentas de apoio à realização de projetos e atividades, principalmente bases de dados e sites de pesquisa acadêmica. No contexto da gestão, o suporte da informática contempla os Sistemas de Informação em Saúde, como o Sistema de Informação de Mortalidade (SIM), Sistema de Informação de Agravos de Notificação (SINAN), Sistema de Informações sobre Nascidos Vivos (SINASC) e o Sistema de Informações da Atenção Básica (SIAB), que são responsáveis pelo planejamento, regulação e controle de dados obtidos na prática cotidiana de profissionais da saúde. Contudo, o aprendizado sobre essas ferramentas durante o processo de formação em Enfermagem e Fisioterapia, em uma disciplina de Informática Aplicada à Saúde, permitiu estabelecer relações entre as TDIC e as ações desenvolvidas por profissionais de saúde.

Um levantamento sobre os trabalhos apresentados no III Simpósio Internacional de Informática em Enfermagem evidencia que os principais temas apresentados descreviam práticas em Educação a Distância (EAD), objetos de aprendizagem e tecnologia em Enfermagem e ensino. A compreensão sobre a dinâmica para melhorar a prática do ensino "contribui para que a utilização e a dependência da tecnologia continuem a se expandir, proporcionando valiosa oportunidade e responsabilidade em produzir e utilizar a informação adequadamente" (TOBASE et al., 2013, p. 78).

\section{Percepções sobre a integração das Tecnologias Digitais de Informação e Comunicação no Ensino de Enfermagem}

As possibilidades de utilização das tecnologias digitais no ensino de graduação em Enfermagem foram investigadas a partir de um curso a distância ofertado sobre a "Introdução às tecnologias educacionais digitais no ensino em Enfermagem" (COGO et al., 2011). Os autores relatam o reconhecimento por parte dos discentes, bem como a importância das tecnologias digitais no ensino, porém, das 30 (trinta) vagas ofertadas, apenas 7 foram preenchidas. A justificativa para a baixa adesão se deve ao fato de os alunos não se sentirem aptos para realizar um curso a distância sem um conhecimento prévio da temática apresentada. Outro aspecto observado nesse estudo é que os recursos foram considerados motivadores e úteis, pois disponibilizam o acesso a novas informações e ajudam no desenvolvimento de habilidades, considerando o foco na aprendizagem do aluno (COGO et al., 2011).

Ao considerar a inserção de novas tecnologias nas práticas de ensino, a percepção se projeta como uma relevante discussão sobre como incluir essas ferramentas interdisciplinares na formação do docente. As mudanças são emergentes quando se percebe uma acomodação das práticas metodológicas tradicionais de ensino, ou seja, quando a falta de conhecimento sobre novas tecnologias pode interferir diretamente na dinamização do processo pedagógico (LEITE et al., 2016). Apesar de percebidas dificuldades para a integração das tecnologias no ensino de Enfermagem, dentre elas, aspectos estruturais e falta de habilidade no uso de algumas ferramentas, os resultados apresentados revelam as suas potencialidades para o processo de ensino-aprendizagem. Os autores reconhecem o quanto essas ferramentas podem ampliar as formas de aprender e fomentar a criticidade na busca por conhecimento. "As TIC ocasionam aprendizagem mais substancial, devido às ferramentas proporcionarem meios auditivos, visuais e interacionais que são atrativos e permitem maior retenção de informações" (LEITE et al., 2016, p.520).

Um estudo que analisou a motivação de alunos de Enfermagem no uso das tecnologias, utilizando a Escala de Avaliação de Fatores de Motivação com Relação à Integração das Tecnologias de Informação e Comunicação ao Ensino (EMITICE), mostrou que as percepções de maior relevância estavam relacionadas a uma dimensão de "Desmotivação", identificando um alto desinteresse por parte dos alunos entrevistados em relação ao uso das TDIC. Tal resultado fora atribuído à não-compreensão da utilização desses recursos, sendo associado a dúvidas sobre a sua aplicabilidade. Já em relação à dimensão “Controle por 
Identificação", os participantes consideraram as TDIC como um recurso que auxilia na qualificação profissional (OLIVEIRA et al., 2017).

Em outra análise acerca da opinião de estudantes quanto à utilização de uma hipermídia educacional sobre punção venosa periférica no ensino de Enfermagem, foi possível identificar quatro categorias: ।. Influência da hipermídia no aprendizado; II. Tecnologia educacional como suporte ao ensino presencial; III. Relação da hipermídia com a prática profissional; IV. Dificuldades de acesso. Na primeira categoria, os alunos ressaltaram a possibilidade de interação entre aluno e professor, além do compartilhamento de suas dúvidas. Outro fator mencionado ainda nessa categoria foi a utilização do ambiente virtual de aprendizagem (AVA), que favoreceu a relação entre a teoria e a prática, proporcionando um aprimoramento do conhecimento sobre punção venosa. Na segunda categoria mencionada no estudo, as tecnologias facilitaram a obtenção de conhecimento, enquanto subsídio interativo, por apresentarem várias possibilidades de aprender. A terceira categoria refere-se ao aumento do desempenho dos serviços prestados aos pacientes, pois facilita a aprendizagem de procedimentos técnicos e o esclarecimento de dúvidas durante sua realização. A última categoria apresenta as dificuldades encontradas pelos discentes; dentre elas, os obstáculos de acesso e a necessidade de uma orientação prévia sobre como utilizar esses ambientes virtuais (FROTA et al., 2014).

Todavia, é importante salientar a necessidade de construir novos espaços de aprendizagem, levando em consideração o diálogo e as possíveis estratégias que podem melhorar os atuais recursos didáticos no processo de ensino-aprendizagem. Além disso, deve-se investir na capacitação dos docentes para manipular as tecnologias de informação e comunicação, tendo em vista que sua utilização requer novas habilidades e competências (COGO et al., 2011; AZEVEDO et al., 2011). Há, sobretudo, uma importante limitação no que se refere à ausência de infraestrutura de informática que contemple as atividades de ensino (AZEVEDO et al., 2011).

Observa-se também uma carência de estudos que revelem o papel do educador no e-learning no campo da Enfermagem (KOCH, 2014). O e-learning em Enfermagem representa uma experiência inovadora, com grandes possibilidades para o ensino e a prática nessa área. Contudo, suas competências precisam ser definidas para que seja possível ampliar a sua aplicação (KOCH, 2014).

O processo de integração das TDIC no ensino de Enfermagem também inclui a educação permanente. Projetos contínuos que promovam a inclusão de "tecnologias educacionais digitais e metodologias ativas a serem aplicadas em cursos de graduação em Enfermagem são de fundamental importância na qualificação desses profissionais" (COGO et al., 2011, p.663).

A presença das TDIC nos diferentes cenários educacionais "implica uma mudança social e cultural que valoriza um novo tipo de saber e exige o conhecimento e domínio de novas habilidades intelectuais e práticas/experienciais" (RIEDNER; PISCHETOLA, 2016, p. 38). Nessa perspectiva, as evidências científicas apresentadas sugerem que a integração das TDIC pode favorecer mudanças nas práticas pedagógicas no ensino de Enfermagem, contribuindo para a aprendizagem e buscando uma maior participação do educando nesse processo de construção de conhecimentos para a prática profissional.

\section{Conclusão}

A produção científica reflete diferentes experiências sobre práticas que integram as TDIC no ensino de Enfermagem. Observa-se que essas ferramentas digitais constituem-se em interfaces que relacionam percepções, desenvolvimento, uso e práticas docentes no ensino de Enfermagem. A motivação de alunos quanto à implementação de novas metodologias, bem como a avaliação sobre possibilidades que relacionam a teoria com a prática, permite criar e desenvolver cenários interativos que contribuem e dão suporte 
ao ensino. Contudo, esse processo de integração requer a mediação de uma proposta pedagógica transformadora que fomente maior participação do educando no processo de ensino-aprendizagem.

A proposta de aplicação das TDIC em diferentes áreas do ensino de Enfermagem se dá com finalidades diversas, tais como a criação de objetos virtuais de aprendizagem, disponibilização de recursos tecnológicos em websites, vídeos, programas computacionais e ambientes virtuais de aprendizagem que operam de forma progressiva para a construção de habilidades dos discentes, de modo a propiciar uma maior participação e articulação de uma aprendizagem significativa. Nesse sentido, oferecem subsídios para ampliar a discussão sobre a integração de novas práticas pedagógicas no ensino de Enfermagem. Contudo, observa-se ainda baixa motivação e/ou adesão de estudantes a experiências que integram as TDIC. Esse resultado permite refletir sobre a necessidade de um processo de articulação contínuo e pedagogicamente fundamentado, uma vez que o uso das tecnologias, por si só, não garante transformação das práticas tradicionais de ensino.

Com isso, ressalta-se que este trabalho trata de uma pesquisa inicial, que parte do interesse em contribuir para mudanças no modelo de formação em saúde, saindo de uma perspectiva tradicional para uma educação problematizadora, que tenha como centro o educando e suas necessidades de aprendizagem. $\mathrm{Na}$ Enfermagem, as evidências distinguem a efetividade das iniciativas realizadas no curso, na modificação e ampliação das relações estabelecidas no processo ensino-aprendizagem, na sala de aula, no laboratório e no acompanhamento de vivências práticas.

\section{Referências}

AZEVEDO, D. M. et al. Recursos de informática no ensino de Enfermagem sob a perspectiva de docentes e gestores universitários. Rev enferm UFPE on-line, v. 5, n. 10, p. 2420-2425, 2011.

BRASIL. Panorama Setorial da Internet. TIC no setor de Saúde: disponibilidade e uso das tecnologias de informação e comunicação em estabelecimentos de saúde brasileiros. Centro de Estudos das Tecnologias da Informação e da Comunicação no Brasil (CETIC), v. 6, n. 1, p. 1-10, 2014.

BRASIL. Resolução CNE/CES $\mathbf{n}^{\circ}$ 3, de 7 de novembro de 2001. DIRETRIZES CURRICULARES NACIONAIS (DCN). Diretrizes Curriculares Nacionais do Curso de Graduação em Enfermagem.

CALIL, F. C. A produção científica de objetos de aprendizagem no ensino em Enfermagem. J. Health Inform, v. 4, n. (Número Especial - SIIENF 2012), p. 138-143, 2012.

CARDOSO, J. P. et al. Construção de uma práxis educativa em informática na saúde para ensino de graduação. Ciência \& Saúde Coletiva, v. 13, n. 1, p. 283-288, 2008.

COGO, A. L. P. et al. Tecnologias digitais no ensino de graduação em Enfermagem: as possibilidades metodológicas por docentes. Rev. Eletr. Enf, v. 13, n. 4, p. 657-664, 2011.

FERNÁNDES-ALEMÁN, J. L. F. et al. Exploring the Use of information and communication Technologies and social networks among university nursing faculty staff. Invest Educ Enferm. v. 32, n. 3, p. 438-450, 2014.

FIGUEIREDO, A. E. Laboratório de Enfermagem: estratégias criativas de simulações como procedimento pedagógico. Rev Enferm UFSM, v. 4, p. 844-849, 2014.

FROTA, N. M. et al. Construção de uma tecnologia educacional para o ensino de Enfermagem sobre punção venosa periférica. Rev Gaúcha Enferm, v. 34, n. 2, p. 29-36, 2013.

FROTA, N. M. et al. Hipermídia educacional sobre punção venosa periférica: perspectiva de acadêmicos de Enfermagem. Cogitare Enfermagem, v. 19, n. 4, p. 717-725, 2014. 
KENSKY, V. M. Educação e Tecnologias: o novo ritmo da informação. Práxis Educativa, Ponta Grossa, v. 7, n. 1, p. 285-290, 2012.

$\mathrm{KOCH}$, L.F. The nursing educator's role in e-learning: a literature. Nurse Educ Today, v.34, n.11, p. 13827, 2014.

LEITE, K. N. S. et al. Uso da tecnologia da informação e comunicação entre docentes à luz da teoria fundamentada nos dados. Rev enferm UFPE on-line, v. 10, n. 2, p. 515-523, 2016.

LOPES, A. M. et al. Congresso Internacional de Educação e Tecnologias: Encontro de Pesquisadores em Educação a Distância, v. 7, n. 1, p. 285-290, 2012, 2018.

MARTINI, J. G. et al. Currículos de cursos de graduação em Enfermagem: revisão integrativa de literatura. J. res.: fundam. care. On-line, v. 9, n. 1, p. 265-272, 2017.

MASSON, V. A. et al. Construção de objetos virtuais de aprendizagem para o ensino da história em Enfermagem. Revista Mineira de Enfermagem, v. 18, n. 3, p. 764-769, 2014.

MENDES, K. D. S.; SILVEIRA, R. C. C. P.; GALVÃO, C. M. Revisão integrativa: método de pesquisa para a incorporação de evidências na saúde e na Enfermagem. Texto Contexto Enferm, v. 17, n. 4, p. 758-764, 2008.

MORI, S.; WHITAKER, I. Y.; MARIN, H. F. Estratégias tecnológicas de ensino associadas ao treinamento em Suporte Básico de Vida. Acta Paul Enferm, v. 24, n. 5, p. 721-725, 2011.

OLIVEIRA, L. M. A. et al. Motivação de alunos de Enfermagem no uso das tecnologias da informação e comunicação. Rev. baiana enferm, v. 31, n. 3, p. 178-198, 2017.

RIBEIRO, R. L. et al. Desenvolvimento de objeto de aprendizagem para o ensino de Anatomia em Enfermagem. Rev Rene, v. 17, n. 6, p. 866-873, 2016.

RIEDNER, D. D. T.; PISCHETOLA, M. Tecnologias Digitais no Ensino Superior: uma possibilidade de inovação e comunicação?. Educação, Formação \& Tecnologias, v. 9. n. 2, p. 37-55, 2016.

SALVADOR, M. E.; SAKUMOTO, M.; MARIN, H. F. Uso do Moodle na Disciplina de Informática em Enfermagem. J. Health Inform, v. 5, n. 4, p. 121-126, 2013.

TOBASE, L. et al. Recursos tecnológicos na educação em Enfermagem. J. Health Inform, v. 5, n. 3, p. 77-81, 2013.

VIDAL, M. N. V. Recursos educativos abiertos para la Comunidad virtual de Enfermería. Educación Médica Superior. v. 29, n. 3, p. 566-575, 2015. 